\title{
Automatic Stability of Aeroplanes
}

\author{
Comments on Some American Patents
}

\author{
By Grover Cleveland Loening, Author of "Monoplanes and Biplanes"
}

A S FLYING becomes more general, the treach1 erous and shifty character of the air-ocean is more and more fully appreciated. The vast swirls and turmoils of the air are felt distinctly' by all aviators, and the manner in which aeroplanes are wafted about on unseen billows and through invisible cross-currents is now familiar to many. One has only to watch for a few moments an aeroplane and its driver in full flight, silhouetted against the blue of the sky, to observe the ceaseless motions of the aviator closely following the equally continuous quivers of his fragile craft.

To fly on a gusty day does indeed tax the nerve and endurance of many men, and it has long been recognized that, although the voluntary control of aeroplanes is well-nigh perfected, yet the disturbing

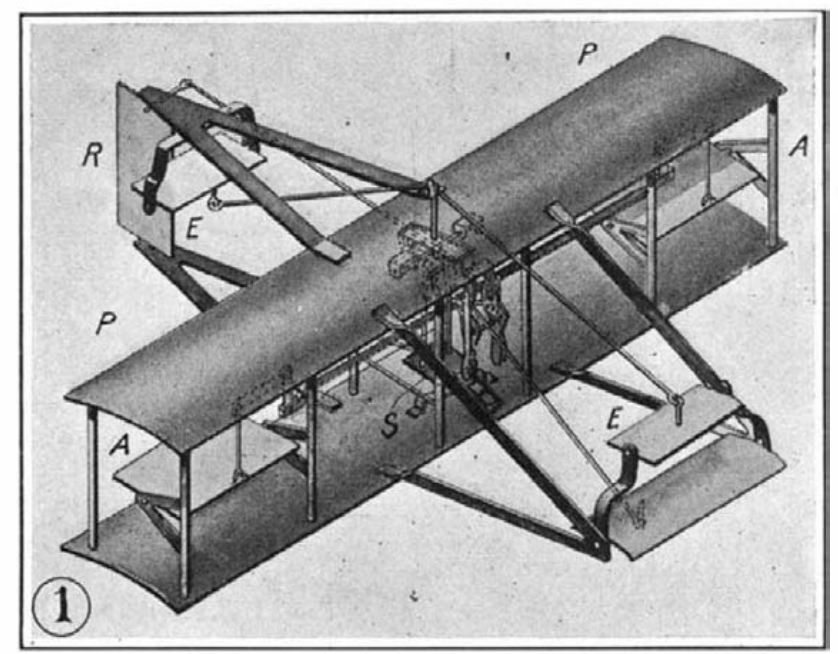

1. The Pressey automatic control.

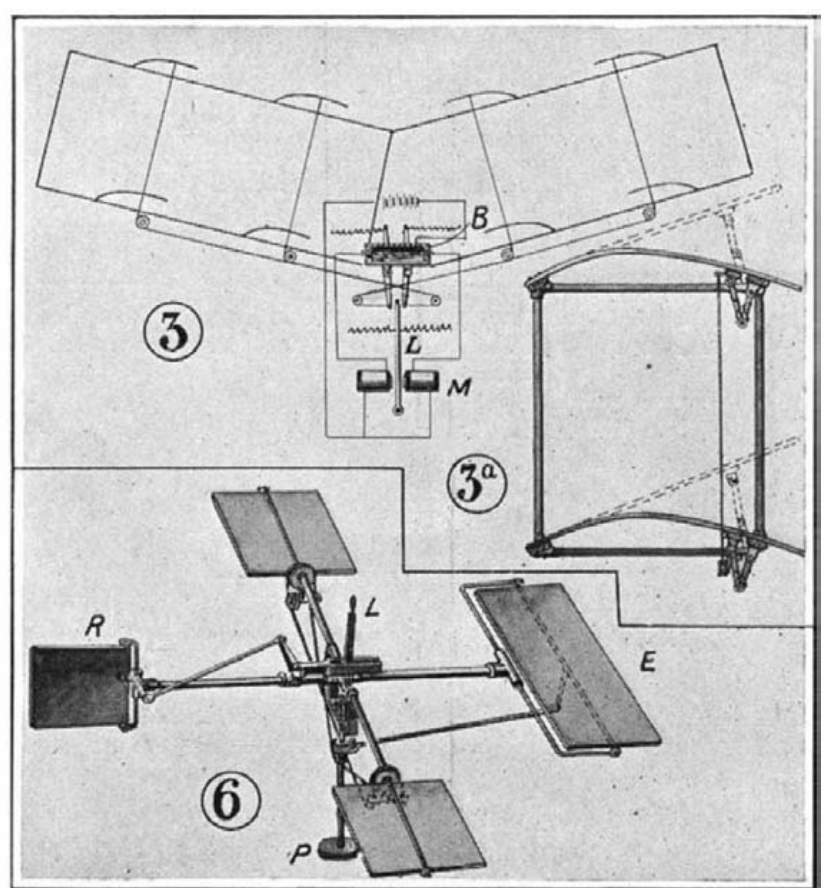

3. The J. D. Pursell patent stabilizing device. 6. Automatic controlling system patented by $P$. R. Torbrand.

air forces are at times so sudden and so powerful that the aviator is taken unawares-often with disastrous consequences.

A great majority hold, therefore, that before flying can become as popular as motoring some practical form of apparatus that will hold the aeroplane in equilibrium automatically must not only be devised, but be applied successfully.

The application of some methods has already taken place, and the actual operation of ther methods that have been devised will doubtlessly come within the year, so that it is appropriate and important to discuss the more noteworthy schemes and some of their particular features as exemplified in the ever-growing list of patents on "automatic stability."

There are numerous methods of attaining this highly desirable end of automatic stability, the most promising ones being:

1. The employment of the inertia of a pendulum or other mass, to move or cause other agencies to move planes or rudders, for correction, as soon as the aeroplane tilts from its normal position of flight. Thi.s method is more generally suggested than any other.
2 The employment of a gyroscopic apparatus which is designed either to hold the machine in perfect equilibrium itself, or else to "precess," and in doin so, move controlling apparatus to correct any tilt.

3. The use of auxiliary planes or light vanes, that travel in the air stream and upon a sudden inclination of the aeroplane, by their continual drifting in about the same line, cause the movement of rudders for the correction of the equilibrium.

4. The construction of the aeroplane of such materials and in such a manner that it possesses of itsel an inherent elasticity, which causes it to be suspended in its element like a carriage on its springs. The Bréguet and Paulhan biplanes are notable types of this kind.

5. A rigid structure of such a form that it possesse a kind of automatic stability. The old Voisin Pischof,. Etrich, Warchalowsky and Dunne ar types of this kind. There may be also included in this class all those types employing the dihe dral principle either laterally or longitudinally.

6. The use of the movement of a compass needle to set apparatus in motion that will move the rudder so as to correct any deviation in direction; and the use of the movement of barometer needle or other apparatus affected by the pressure of the air to control the rudders for altitude.

The manner in which a pendulum device is relied upon to give automatic control is best shown by reference to Figs. 12, 13 and 14. Fig. 12 represents a longitudinal section of an aeroplane, showing a pendulum control $P$ for for and aft balance and an elevator rudder $E$. Th direction of flight is indicated by the arrow, and in this same diagram the aeroplane is assumed to be in normal horizontal flight.

Fig. 13 shows the same apparatus immediately after a sudden gust has tilted the front of the machine up. The pendulum $P$, due to its inertia, has retained its vertical position $P^{1}$, but in doing so has pulled on the rod $a d$, causing the front elevator to assume the position $E^{1}$, and to receive the pressure of the wind on its upper face. This causes a downward force on the rudder surface which brings the machine back to the horizontal Fig. 14 represents the effect of a sudden downward plunge of the head of the machine.

In the same manner, the inertia of the pen dulum is used to move side controls, when sudden transverse tilt occurs.

Of course the nature of the pendulum and the manner in which it controls the equilibrium is vastly different in many of the suggested methods, but the fundamental principle is everywhere the same, the pendulum itself consisting variously of an extra weight, the weight of the car, th weight of the aviator, swinging on a movable seat, or the movement of a mercury bath.

There are four distinct objections to employing any kind of a pendulum device for automati stability:

(a) The first and most important objection is that, if the pendulum is at all heavy, it will tend when the machine is tilted, to accentuate greatl the tipping. Thus, in Fig. 13, due to the fact that the weight $P^{1}$ has traveled through an angle $O$ with respect to the frame, there will be a stron downward pull in the direction $B A$. 'This will certainly accentuate the downward force at the rear due to the vertically downward component $B C$. If the weight is heavy enough and the inclination great enough this is likely to completely unbalance the machine.

(b) Another effect upon a pendulum mechanism that makes it distinctly undesirable is that if there is a sudden lurch of the entire machine either for ward or backward, or to either side, unaccompanied by any tilting, then the inertia of the pendulum will cause it to swing away from the side to which the machine lurches, thus moving the rudders and actually disturbing the equilibrium of the machine by either making it rise, plunge or tilt over to one side Due to "holes in the air," sudden side gusts and even variable propeller thrusts, such sudden lurches ar of frequent occurrence, and unless some means of "deadening" the pendulum is provided the equilibrium would be very unstable.

(c) The action of centrifugal force un making a turn will cause the pendulum to assume a position parallel to the struts of the machine or any other normally vertical parts, and it will not fly out to the outside as commonly supposed. Its action in turning, therefore, is nil, and to make the turn positive it would be necessary to install a separate control. This arrangement assumes a proper "banking" of the machine.

(d) After any displacement of the pendulum itself from its normal position due to a sudden movement or lurch of the aeroplane, the pendulum will at once tend to swing back to the normal. If the period of this swing should just happen to coincide with the frequency of any vibration or sway' in the machine or with any wave pulsations of the air stream, then the swinging would continue and be amplified, eventu.

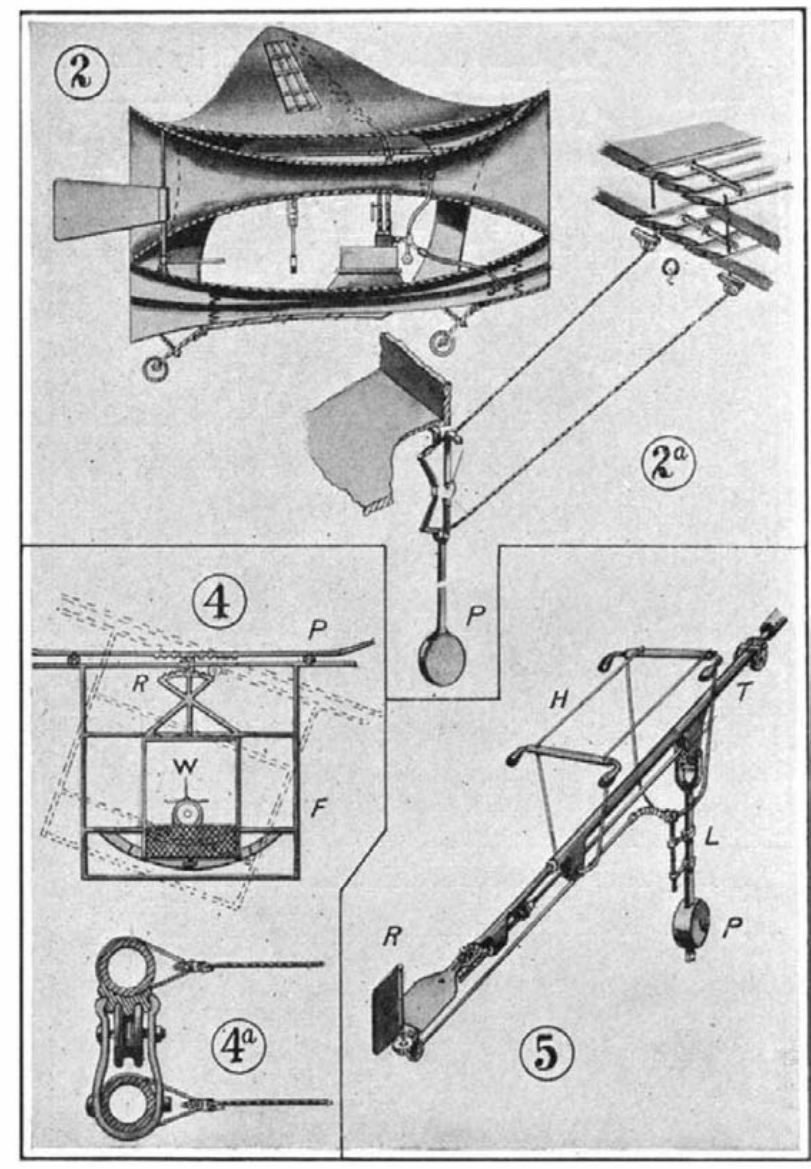

2. The C. I. Lake apparatus. 4. The pivoted plane devic patented by F. H. Wales. 5. The James Means patented penqulum system of automatic centrol.

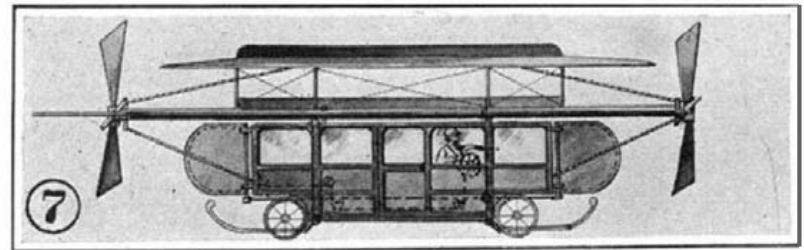

7. A typical example of an early patented flying machine. ally destroying the equilibrium of the machine. Syn chronism of this sort is not at all unlikely to happen, for air waves are known to possess pulsations at regular time intervals; and in addition, propellers have often been found to give continuously and rhythmically varying thrusts, causing a slow swaying vibra. tion in the aeroplane, quite distinct from the vibration of the motor.

It appears, therefore, that the use of a pendulum for preserving the stability of an aeroplane is limited in its action to the condition of comparatively steady horizontal flight, and is hardly feasible in very gusty weather.

One of the earliest devices of this sort (Fig. 11) was patented by E. P. Johnston on June 5th, 1888 (U. S. Patent No. 383,889). The flying machine described is of the helicopter type, in that it is provided with four lifting shown. Any inclination of the ship either transversely or longitudinally sets a pendulum in motion, which, by means of an electric contact, governs the operation of the motive power to the propellers, so that the lift on the depressed side is increased. In addition, it is interesting to note that the patent covers the shifting of the pendulum $\boldsymbol{P}$, causing a 
movement of a needle $N$ on a dial $D$, thus indicating to the operator the state of equilibrium of the machine.

A similar electrical control of the power supplied to lifting propellers by a pendulum, was patented in England by I. A. Colquhoun on July 29th, 1907. Sir Hiram Maxim, on April 28th, 1897, patented, in Eng land, a pendulum device actuated by the tilting of the machine, and thus controlling the power of the engines which drive the propellers so that the machine is automatically righted.

Sylvanus S. Morrison, on October 11th, 1910, patented a device.

(see Fig. 10),

in which the

plane is piv-

oted to $\mathrm{tho}$

chassis (U. S.

patent

$395)$. The chas-

sis $C$, due to

is

stay in a nor-

mal position.

The tilting of

the plane ${ }^{3}$

down on any

side, by means

of a suitable

system of

levers, shafts

and g e a r s,

causes the en-

tire motor and

ordinary ver.

tical propeller

system $S$ to be

turned arouni

on a horizon-

so $\mathrm{that}$ the

thrust of the

propeller a nd

the air thrown

back by it, is directed against the lowered side, thus, due to the increased draught of air, causing it to lift up.

On March 27th, 1906, the I. C. Hansen-Ellehammer device was patented in England. It consists merely of the system shown in Figs. 12,13 and 14, in whicin a simple weight is connected by a rod to an elevation rudder, and upon the tilting of the machine up or down the inertia of the weight causes the rudder to be moved for correction.

The employment of the movement of a mercury bath instead of a weight was patented by I. D. Pursell on October 22nd, 1907 (U. S. patent No 869,019). The mercury is contained in a barrel $B$ (see Fig. 3), and when the aeroplane tilts the mercury runs to the lowered end of the barrel, thus closing a circuit and operating an electromagnet $M$, which moves a lever $L$, causing the rudders or side warping control to be set for correction of the equilibrium.

The C. I. Lake patent of April 13th, 1909 (U. S patent No. 918,336), covers essentially a fluid jet propelled apparatus (see Fig. 2) equipped with a pendulum $P$ (Fig. 2a) caused to swing by the tilting of the machine, and by thus opening certain passages and changing the fluid movement, the apparatus is brought back to an even keel.

F. H. Wales, on August 2nd, 1910, patented a system for automatic stability' (U. S. patent No 965,969). The car or other heavy movable weight $W$ (see Fig. 4) is pivoted to the frame $F$, and upon the tilting of the machine to any side the car, remaining normal, causes the entire plane $P$ to be shifted bodily over to the depressed side by means of a toothed segment and rack $R$. The lift on the depressed side is thus increased.

On December 14th, 1909, the pioneer James Means patented a pendulum device that has many advantages because all the movements of the pendulum $P$ (Fig. 5) and rudders $R$ are easily in control of the aviator through a handle bar $H$, which is part of the pendulum lever and moves with it, thus preventing eccentric motions of the pendulum. In addition, positive volunt If the aeroplane plunges head down, the pendulum $P$ swings forward (with respect to the frame), and by means of a gear and rack it turns the rear elevation rudder for ascent. If there is a sudden tilt down to one side the pendulum turns a tube $T$, fitted with bevel gearing, in such a manner that the side ailerons are moved inversely for correction of the tilt.

The P. R. Torbrand automatic control, patented on September 20th, 1910 (U. S. patent No. 970,974), is similar in many respects to the Means device. The pendulum $P$ (Fig 6 ) controls the lateral and longitudinal equilibrium by movement of ailerons and rudders. A lever $L$, when moved forward and back, gives voluntary control of the elevation rudder $E$ and con- trols the rear direction rudder $R$ by side-to-side motion. There is no voluntary control of the lateral equilibrium, however, in this derice, the pendulum alone being relied upon to keep the machine on in even keel transversely.

The well-known automatic control of the Wrights, patented both here and abroad, relies upon the move ment of a pendulum mechanism caused by the iatera tilting of the aeroplane, which actuates a valve controlling the admission of compressed air to a cylinder, thus moving a piston and by' suitable connection operating the warping of the planes and the rudder. will cause great internal stress in the framework supporting it, and will only slightly affect the equilibrium, while it is certain that turning in any direction would ke practically impossible if the gyroscope is strong enough.

But if a light gyroscopic apparatus is installed, capable only' of operation of the controls by its motion f precession, there is great possibility of an abso. lutely automatic stability. The Marmonnier and Reg. nard gyroscopes are devices of this sort. Up to the present, however, such devices have been found very delicate and difficult to handle, and the refinement reuired in their quired in their great and expensive, while in any very turbulent condition of the air the action becomes so complicated $\mathrm{that}$ the apparatus merely jerks the rudders in every conceivable direction. ple and effective means of using gyroscopic force, $\mathrm{h}$ ow e ver, is that described in the patent of A. M. Herplane is equip. ped with two propellers rotating in opposite directions as on the Wright ma. chine. The
(11)

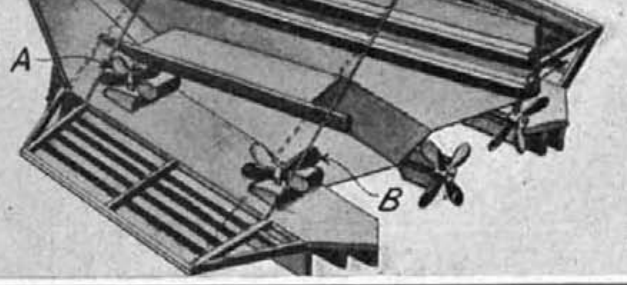

ane
The Pressey automatic control (see Fig. 1) is about the simplest and most effective yet devised. In this system very little weight is added, since the pendulum weight $S$ consists of the aviator seated in a swinging seat. Any sudden tilt of the machine cause him to swing in such manner with reference to the nlanes $P P$ that the usual rudder or aileron operation at once takes place. In addition provision is made for "locking" the seat, thus enabling voluntary control of ascent or descent. $A A$ are the ailerons, $E E$ the elevation rudders and $R$ the direction rudder.

The precession action of the gyroscope offers an excellent solution to the problem of automatic equilibrium, but its action is so complicated that if its opera tion is not thoroughly understood there is likely to be great confusion in the preservation of the equilibrium. When any disturbance occurs, there is little doubt that a gyroscope solidly fixed to an aeroplane

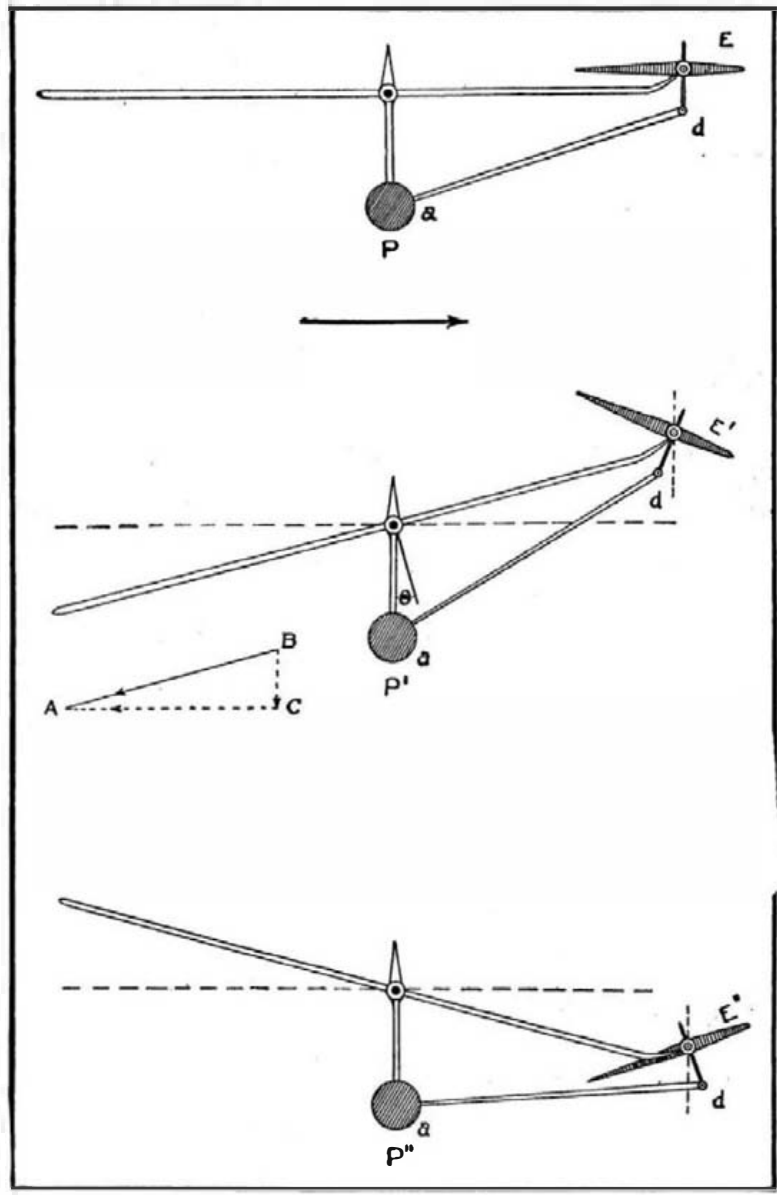

Figs. 12, 13, and 14. - Showing the manner in which pendulum preserves stability.

propeller shafts are mounted on ball and socket joints in such fashion that they can swing in a horizontal plane without affecting the drive from the motor shafts. The propeller shafts are prevented from swinging in vertical planes. When the aeroplane in flight tilts up or down, longitudinally, the propeller shafts, due to gyroscopic action, will either swing toward each other or away from each other. This movement is communicated to the elevation rudder by suitable means and causes it to right the machine. III.

The employment of auxiliary planes or vanes that are designed to fly out in the air stream under all conditions of equilibrium of the aeroplane is a very simple method of attaining automatic stability, and one that promises much, as soon as the actual natur? of the stream flow about an aeroplane is fully determined.

Capt. Etévé recently installed a device of this kins on his French Wright machine. A light hinged vane was permitted to flap freely in the air stream at the rear of the aeroplane, and was connected to the elevation rudder at the front by a lever system. Whenever the aeroplane tilted longitudinally the vane caused the rudder to move in such a manner that the machine was righted.

The Wright automatic stability patent makes use of a vane of this kind for longitudinal equilibrium, the movement of the vane actuating a valve controlling the compressed air supply to a cylinder, the piston of which operates the elevation rudder.

Elasticity of structure of the planes, as on the Paulhan and Bréguet, gives a certain degree of stability. A sudden downward gust on one side, for example, due to the great flexibility and "give" of the plane, will increase the angle of incidence on that side, thus momentarily increasing the lift and counteracting the depressing effect of the gust.

On the Bréguet the rear cruciform tail is mounted and held by light springs. A sudden upward gust on the tail will thus cause it to give way' a little and be turned in such a manner that the increase of air pressure on the upper horizontal face will force it down, counteracting the upward gust. This is an admirable provision, and gives a remarkable degree of stability.

The "box kite" structure of the old Voisin type and the consequent hold it had on the air is well known, as is also the upturned wing ends of the Pischoff, Etrich and Warchalowsky aeroplanes and the manner in which they tend to automatically hold the machine on an even keel. The Dunne principle of a V-shaped 


\section{A WELL SECURED INVESTMENT}

NETTING OVER $5 \%$

First mortgage bonds in $\$ 500$ and $\$ 1,400$ denominations secured by assets
of over five times the amount of the issue. 'The Company's net earnings pal and interest tequirements. The investment behind the bonds over $\$ 3,000,000$, or more than two and a half times the total bond is. sue of $\$ 1,200,000$. 'The mortgage contains anl ample sinking fund provision. During the month of Febru-
ary, the first month after these bond ary, the first month after these bonds
were issued, the sinking fund actually paid in was practically three times the renthly requirenient to mieet the cur management of the Company is thoroughly experiericed and successfil.
The bonds mature in equal sentiannual installments from six nionth matgin of security will ralpidly increstse

\section{revilar No: $\mathbf{7 a z a}$}

\section{Peabody;}

Houghteling \&Co.

(Established 1865) 105 S. La Salle St., Chicago

\section{Solders and Soldering}

9I If you want a complete text book on Solderis and

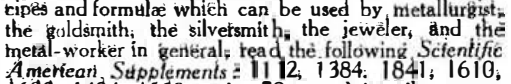

$162 z_{3} 1434_{3} 1533$; priee 70 cents by nat

MUNN \& COMPANY, Inc.

\section{Yours for the asking

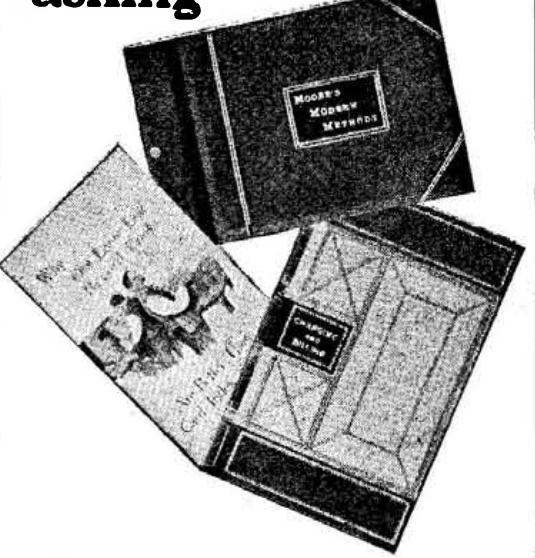 \\ Complete Loose \\ Leaf Library}

Covering the entire subject of Loose Leaf Record Keeping

These books (200 pages) contain illustrations of 40 different record forms and fully describe their use: give full information how to start the Loose Leaf System and how to maintain it. They will show you how

\section{Moore's Modern} Methods

reduceofficework and expense; whythis Loose Leaf System is used by 60,000 progressive business houses today.

We shall be glad to send any business or professional
man these books without charge or obligation.
You cannot buy more complete information on Loose You cannot buy more complete information on Loose
Leaf methods than we give you in this library. Fill out JOHN C. MOORE CORPORATION EST ABLIBHED 1839
685 Stone Street, Rochester,

COUPON-

\section{Octave Chanute}

(Continued from page

\section{Mr. Chanute forwarded a quantity}

aeronautic literature, visited the camp Wilbur Wright and his brother Orville made their first glider experiments, an
continued their steadfast mentor till they had transformed the glider into a true dynamic aeroplane.

Similar counsel and friendily sympathy was extende to sone of the pioneer ${ }^{\circ}$ given to the promotion of aviation with-
aeroplanists in Europe, who likewise
out prospect of return, not to mention succeeded ere long in powering the many times that amount of his raluable Challute silider and trànsfơrming it into profesional time. Thus by virtue of a successful dyilainic biplane. In fact his own inventions and researches, and during the first decade of the twentieth by virtue of his thost generous and symcentury the developnient of the light pathetic assistance of all earnest votaries gasoline engine hád ẩivanced sô far of the art, he has doubly merited the that every clever mechanic who had title sonetimes applied to him by his mokiey enough to jrocure a good one, of countrymen-"The Father of Aviation."

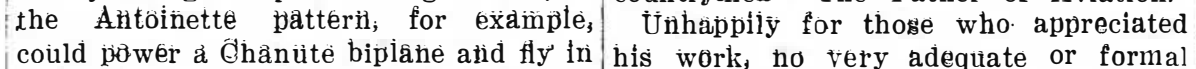
could power a chan we biplane atid fly in his work, no tery adequate or formal
fair weather: This was weil showtl by
recognition of his earnest and imfair weather: This was well sh6wth by
severál brisk young men in Fiłance, and
portant labors in aerorautics was made in jarticilar by the farious aeronalut by his countrymen during his lifetime. Santos-Diimont, whö; without spectial pre- This perhaps is due to the fact that he liminary training in aviation, and while was taken from their midst so shortly' others were cautiously studying safe after the science of mechanical flight bemethods, suddenly bolted into the air gan to assume great value in the general the helds of his astonished friends by that sheer audacity and awkwardness, but lish a suitable memorial of his long deably seconded by his marvelous Antoin- votion and flne achievements in a sciette moto

One naturally inquires why $\mathrm{Mr}$.

owi. The reason was simply that when

a light inbtor was first available he had Automatic Stability of Aeroplanes passed three score anid ten. He was now plane ând too scrupulous to invite atly plane and too scrupulous to invite afly coinpleted his intportant pioneer work and was serenely watching the y'ounger
generation of men ds they appeared on generation of men dis they appeared on the scene one by one, then by scores, to
enjoy the fruits of his labor and that of his confrères, Lilienthal, Pilcher, Langley and others who had helped

\section{pare the way for final success.} his death on Thanksgiving ar most sanguine dreams more than realized. Flyers were traveling from city to
city at more than railway speed; sweep.

\section{ing over vast stretches of water and un-} known territory, guided through fog and
tempest by the simple mariners' com. tempest by the simple mariners' com.
pass; aoaring like eagles above the rain clouds and in regions white with frost; racing over the Alps; contending in great tournaments; maneuvering with great tournaments; maneuvering with military establishments of the world. He military establishments of the world. He differently from land or water, nor to see a dozen passengers in one machine,
nor an aviator of less than a y'ear's training fly without pause from London to
Paris, through fair and foul weather, at more than a mile per minute; but these
things he could easily anticipate, and much more that still remains to be accomplished.

One favorite dream of his that still of soaring flight. He was convinced that movement of a compass needle which the great vultures, gulls and powerful motor to turn the rudder so as to keep birds of prey can in favorable weather the machine on a steady course

ride the wind for hours without wing- Such devices are highly ingenious, but beat or the expenditure of propulsive their pract
power. Indeed, one incentive to his glid- termined.

ing experiments was the hope to pro-

mote the art of human soaring. And one
of his latest papers published in Aeronautics, two years before his death,
demonstrated the feasibility of soaring $\mathbf{M}_{\text {ing almost every fine day in Lon }}^{\mathrm{R} \text {. EARLE OVINGTON, who is fly }}$

Earle Ovington's Blériot in a wind having an upward trend of Island, has brought to this country the three to four feet per second. He first of the new 1911, 70 horse-power
wished to have young men take up glid- Blériots. The machine is fitted with a wishe to have young men take up glidable to such art, particularly where a first of which was made by the Gnome steady breeze flows up a sandy slope by Company for Blériot's passenger mathe sea, hoping that they might eventu- chine, and the second for Farman. Mr. condor and the albatross. Perhaps ere curve tail, which will characterize all long that dream, too, may be realized, the 1911 single-place Blériot monoplanes. when the talented volplanists of the Mr. Ovington is an engineer, and has present hour turn from their dynamic had special features incorporated, prinmachines for a vacation's contest with $\begin{aligned} & \text { cipally to strengthen the construction. } \\ & \text { the vultures and the gulls. }\end{aligned}$
Instead of the four steel straps under \begin{tabular}{l|l} 
the vultures and the gulls. & Instead of the four steel straps under \\
The foregoing is but a partial glimpse & the wings, he has had six fitted. Two
\end{tabular} of Mr. Chanute's ceaseless activity in extra main spars run the whole length aviation during the last twenty years of the wings. There are just twice as of his life. His most arduous, and next many ribs as in the wings on the or to the glider experiments, perhaps his dinary 50-horse-power Blériots. Every
most effective efforts were exerted to control wire on the machine is in dupli-

\section{HEATS \\ Hard-to-Heat HOUSES}

IIf your house is difficult to heat or you have rooms diffcult to heat
there is added reason for putting in

\section{KELSEY} ${ }_{\text {AIR }}^{\text {WARM }_{\text {M }} \text { Generator }}$

T The Kelsey has been supremely
successful in heating homes on hills
or in exposed locations and the
most distant rooms can be perfectly
heated. Proof of this is absolute.

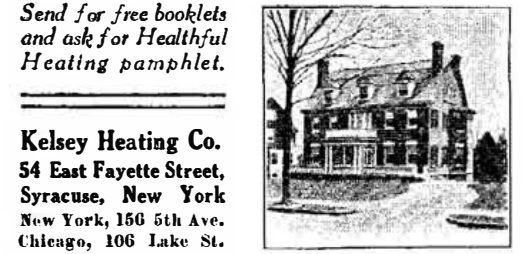

N.w York, 156 5th Ar.

EASY TO BUY S1O Our monthly payment plan makes it
easy for anyone to have the best heating easy for anyone to have the best healing big profits and excessive charges for instal-
lation and repairs. Saves one-third the cost. JAHANT Down Draft FURKACE For residences, schools, hotels, churches, etc.
sold Under a Binding "Guaranty Bond" to
give perfect satisfaction after 365 days' use or
goney refunded. We send
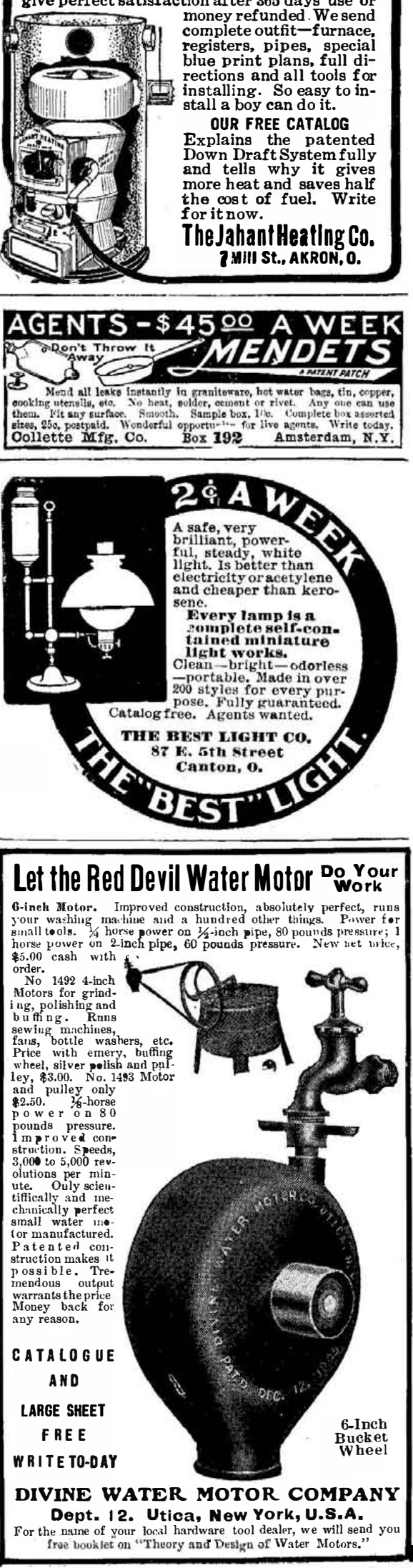